\title{
ChemComm
}

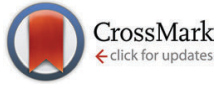

Cite this: Chem. Commun., 2015, 51, 101

Received 21st October 2014, Accepted 5th November 2014

DOI: $10.1039 / c 4 c c 08312 a$

www.rsc.org/chemcomm

\section{The first near-linear bis(amide) f-block complex: a blueprint for a high temperature single molecule magnet $\dagger$}

\author{
Nicholas F. Chilton, Conrad A. P. Goodwin, David P. Mills* and \\ Richard E. P. Winpenny*
}

\begin{abstract}
We report the first near-linear bis(amide) $4 f$-block compound and show that this novel structure, if implemented with dysprosium(III), would have unprecedented single molecule magnet (SMM) properties with an energy barrier, $U_{\text {eff }}$ for reorientation of magnetization of $1800 \mathrm{~cm}^{-1}$.
\end{abstract}

Since their initial discovery, ${ }^{1}$ single molecule magnets (SMMs) have been lauded as candidates for high density data storage devices. ${ }^{2}$ A major breakthrough in the field ${ }^{3}$ occurred in 2003 with the observation of SMM behavior in a monometallic $\left\{\mathrm{TbPc}_{2}\right\}^{-}$ complex with an energy barrier, $U_{\text {eff }}=230 \mathrm{~cm}^{-1}$. The ensuing decade saw rapid growth in lanthanide $S M M^{5}$ with the $U_{\text {eff }}$ barrier to magnetization reversal increased to $652 \mathrm{~cm}^{-1}$ for another derivative of $\left\{\mathrm{TbPc}_{2}\right\},{ }^{6}$ and $585 \mathrm{~cm}^{-1}$ for a polymetallic Dy@ $\left\{\mathrm{Y}_{4} \mathrm{~K}_{2}\right\}$ complex. $^{7}$ The highest blocking temperature $T_{\mathrm{B}}$ (i.e. the temperature at which hysteresis is observed) was also increased to $14 \mathrm{~K}$, via an $\mathrm{N}_{2}{ }^{3-\bullet}$ radical bridge in a $\left\{\mathrm{Tb}_{2} \mathrm{~N}_{2}{ }^{3-\bullet}\right\}$ complex. ${ }^{8}$

Although three of these milestones employ the $\mathrm{Tb}^{\mathrm{III}}$ ion, by far the most utilized lanthanide ion in SMMs is Dy ${ }^{\mathrm{III}}$ by virtue of its unique electronic structure. ${ }^{9}$ Apart from a radical-bridged $\left\{\mathrm{Dy}_{2} \mathrm{~N}_{2}{ }^{3-\bullet}\right\}$ complex, ${ }^{10}$ nearly all polymetallic Dy ${ }^{\text {III-based SMMs }}$ possess negligible interactions between magnetic spin centres, and instead rely on the single ion anisotropy of Dy" ${ }^{\text {III }}$ (i.e. the local crystal field environment) to provide the barrier to the reversal of magnetization. Intra- or intermolecular interactions are often detrimental to the performance of Dy ${ }^{\mathrm{III}}$ SMMs so that doping a small amount of the paramagnetic ion into a diamagnetic host lattice (usually the $\mathrm{Y}^{\mathrm{III}}$ analogue) often results in an increased $U_{\text {eff. }}{ }^{7}$

An electrostatic model for the design of ideal ligand environments to exploit the maximal anisotropy of Dy ${ }^{\text {III }}$ has been postulated, ${ }^{11,12}$ and shown to be in good agreement with multiconfigurational complete active space Self consistent field

School of Chemistry, The University of Manchester, Oxford Road, Manchester, M13 9PL, UK. E-mail: richard.winpenny@manchester.ac.uk,

david.mills@manchester.ac.uk

$\dagger$ Electronic supplementary information (ESI) available: Full synthetic details, crystallography, NMR spectroscopy, magnetism, and ab initio and magnetic relaxation methodologies. CCDC 1017031. For ESI and crystallographic data in CIF or other electronic format see DOI: 10.1039/c4cc08312a
(CASSCF) $a b$ initio calculations ${ }^{12}$ that are often employed to examine $4 \mathrm{f}$ complexes, pioneered by Chibotaru. ${ }^{7,13}$ Electrostatic approaches suggest that the optimal ligand environment to exploit the oblate spheroidal electron density of Dy ${ }^{\mathrm{III}}$ is axial, where rigorously axial systems have the benefit of maintaining a single, unique quantization axis for the total angular momentum $m_{J}$ states. $^{14} \mathrm{~A}$ set of unadulterated $m_{J}$ states implies that the probability of quantum tunnelling of the magnetization (QTM) is reduced, therefore increasing magnetic relaxation times. ${ }^{2}$

The simplest axial ligand environment is a linear two-coordinate complex with donor atoms exclusively on a single Cartesian axis; the $U_{\text {eff }}$ barrier is so large for the $\left\{\mathrm{Dy}_{5}\right\}$ and $\left\{\mathrm{Dy}_{4} \mathrm{~K}_{2}\right\}$ alkoxide complexes ${ }^{7}$ because of the strongly axially repulsive crystal field potentials along the local $z$-direction of each Dy ${ }^{\mathrm{III}}$. Other compounds such as $\left[\left(\mathrm{C}_{8} \mathrm{H}_{8}\right)_{2} \mathrm{Ln}\right]^{-}$(ref. 15) or Cloke's bis(arene) lanthanide complexes ${ }^{16}$ are sometimes described as linear, but lack donor atoms directly on the axis. Linear 3d-metal compounds also show remarkable magnetic behaviour with very high $U_{\text {eff }}$ values. ${ }^{17}$ A one coordinate lanthanide complex $[\mathrm{DyO}]^{+}$has been considered theoretically with a very large $U_{\text {eff }}$ predicted, ${ }^{14}$ however such an entity is not chemically feasible.

Very low coordination numbers for 4f-ions are difficult to achieve as these are large, electropositive ions, which require a sterically demanding ligand. Such a pro-ligand $\mathrm{HN}\left(\mathrm{Si}^{\mathrm{i}} \mathrm{Pr}_{3}\right)_{2}$ was designed, and synthesised from $\mathrm{ClSi}^{i} \mathrm{Pr}_{3}$ and $\operatorname{LiHN}\left(\mathrm{Si}^{\mathrm{i}} \mathrm{Pr}_{3}\right)$, and this was converted to the group 1 transfer agent $\left[\mathrm{KN}\left(\mathrm{Si}^{\mathrm{i}} \mathrm{Pr}_{3}\right)_{2}\right]$ with $\mathrm{KH}$. Reacting two equivalents of $\left[\mathrm{KN}\left(\mathrm{Si}^{\mathrm{i}} \mathrm{Pr}_{3}\right)_{2}\right]$ with samarium(II) diiodide yields the mononuclear homoleptic bis(amide) complex, $\left.\left[{ }^{\mathrm{i}} \mathrm{Pr}_{3} \mathrm{Si}\right)_{2} \mathrm{~N}-\mathrm{Sm}-\mathrm{N}\left(\mathrm{Si}^{\mathrm{i}} \mathrm{Pr}_{3}\right)_{2}\right] 1$ (Fig. 1, see ESI $\dagger$ for details).

Complex 1 is the first near-linear f-element complex, with an $\mathrm{N}-\mathrm{Sm}-\mathrm{N}$ angle of $175.52(18)^{\circ}$ in the solid state (Fig. 2, see ESI $\dagger$ for details); this near-linearity contrasts with the bent C-Ln-C angles of $\left[\mathrm{Ln}^{\mathrm{II}}\left\{\mathrm{C}\left(\mathrm{SiMe}_{3}\right)_{3}\right\}_{2}\right]$ complexes $(\mathrm{Ln}=\mathrm{Sm}, \mathrm{Yb}, \mathrm{Eu}){ }^{18-20}$ The

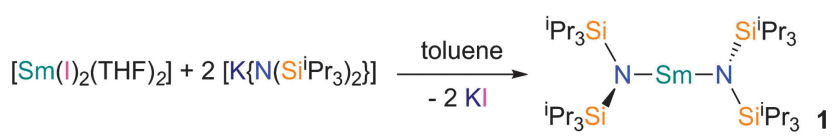

Fig. 1 Synthetic route to 1. 


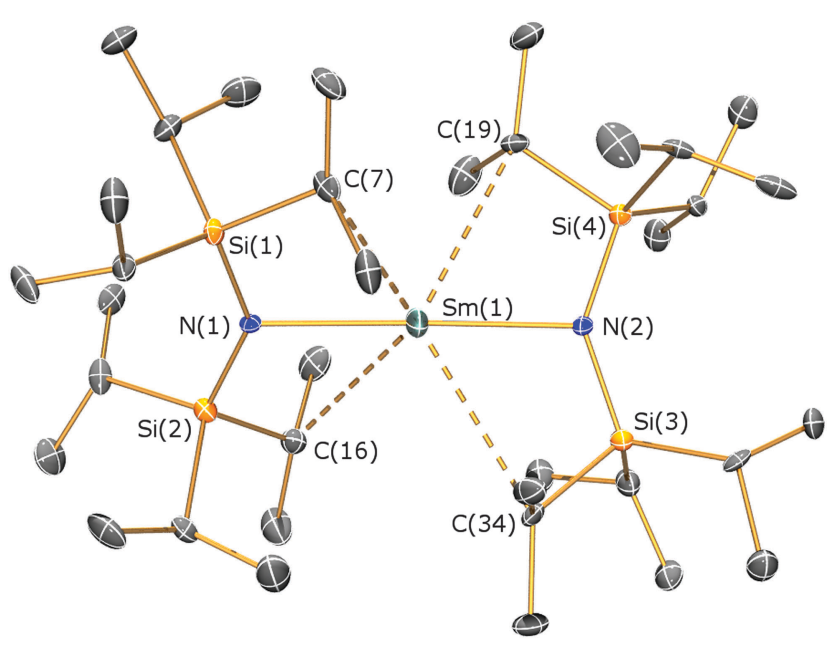

Fig. 2 Molecular structure of 1 . Hydrogen atoms omitted for clarity. Selected bond lengths $(\AA)$ and angles $\left({ }^{\circ}\right)$ : Sm1-N1 2.483(6), Sm1N2 2.483(6), Sm1‥C7 3.180(8), Sm1‥C16 3.169(8), Sm1…C19 3.082(8), Sm1 ‥C34 3.224(8), N1-Sm1-N2 175.52(18), Sm1-N1-Si1 109.9(3), Sm1$\mathrm{N} 1-\mathrm{Si} 2$ 111.6(3), Si1-N1-Si2 138.5(4), Sm1-N2-Si3 109.8(4), Sm1-N2-Si4 110.8(3), Si3-N2-Si4 138.8(4).

bulky ${ }^{\mathrm{i}} \mathrm{Pr}$ groups are vital for the isolation of a homoleptic complex, as $\left[\mathrm{Sm}\left\{\mathrm{N}\left(\mathrm{SiMe}_{3}\right)_{2}\right\}_{2}(\mathrm{THF})_{2}\right]$ exhibits additional O-donors. ${ }^{21}$ The Sm-N distances in 1 [2.483(6) $\AA]$ are longer than those observed in $\left[\mathrm{Sm}\left\{\mathrm{N}\left(\mathrm{SiMe}_{3}\right)_{2}\right\}_{2}(\mathrm{THF})_{2}\right]$ [mean $\mathrm{Sm}-\mathrm{N}$ 2.433(9) $\AA$ ] but this is compensated by 1 exhibiting four short $\mathrm{Sm} \cdot \mathrm{C}_{\text {methine }}$ distances

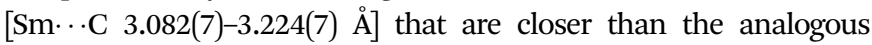
$\mathrm{Sm} \cdots \mathrm{C}_{\text {methyl }}$ contacts observed in $\left[\mathrm{Sm}\left\{\mathrm{N}\left(\mathrm{SiMe}_{3}\right)_{2}\right\}_{2}(\mathrm{THF})_{2}\right][\mathrm{Sm} \cdots \mathrm{C}$ 3.32(1)-3.46(1) $\mathrm{A}] .^{21}$ The approximately planar $\mathrm{SmNSi}_{2}$ fragments in 1 are staggered with respect to each other (twist angle of $44.42^{\circ}$ ), with the deviation from $90^{\circ}$ attributed to agostic $\mathrm{Sm} \cdots \mathrm{C}_{\text {methine }}$ interactions.

Formally each nitrogen atom carries a single negative charge and the $\mathrm{Sm}^{\mathrm{II}}$ ion is divalent, with an $[\mathrm{Xe}] 4 \mathrm{f}^{6}$ configuration. The $\mathrm{f}^{6}$ configuration leads to a formally diamagnetic ${ }^{7} \mathrm{~F}_{0}$ ground state, with close lying excited states that provide a non-zero magnetic moment at room temperature. Magnetic measurements on $\mathbf{1}$ give a room temperature magnetic moment of $3.62 \mu_{\mathrm{B}}$ that falls towards zero at low temperature (Fig. S2 and S3, ESI $\dagger$ ). This is clearly incompatible with interesting low temperature magnetic behaviour. However, the structure of $\mathbf{1}$ is close to the ideal linear arrangement to stabilize the large angular momentum states of Dy ${ }^{\text {III }}$ and produce monstrous uniaxial magnetic anisotropy.

Such a Dy ${ }^{\text {III }}$ compound is challenging to make; we believe a route via the heteroleptic $\left[\mathrm{Dy}\left\{\mathrm{N}\left(\mathrm{Si}^{\mathrm{i}} \mathrm{Pr}_{3}\right)_{2}\right\}_{2} \mathrm{I}\right]$ treated with the potassium salt of a large anion might work through precipitation of a potassium iodide. Other routes can be imagined, and here we present predictions of the magnetic properties of such a complex, intending to inspire synthetic work towards the linear Dy ${ }^{\text {III }}$ complex, and, more ambitiously, the isoelectronic $\mathrm{Tb}^{\mathrm{II}}$ analogue.

The properties of $\left[\left({ }^{\mathrm{i}} \mathrm{Pr}_{3} \mathrm{Si}\right)_{2} \mathrm{~N}-\mathrm{Dy}-\mathrm{N}\left(\mathrm{Si}^{\mathrm{i}} \mathrm{Pr}_{3}\right)_{2}\right]^{+} 2$ are predicted by CASSCF/RASSI/SINGLE_ANISO ${ }^{22} a b$ initio calculations (see ESI $\dagger$ for details) employing the structure of $\mathbf{1}$, where $\mathrm{Sm}^{\mathrm{II}}$ has been replaced by Dy II. The validity of the method was tested by calculating the variable temperature magnetic behavior of $\mathbf{1}$, where the agreement

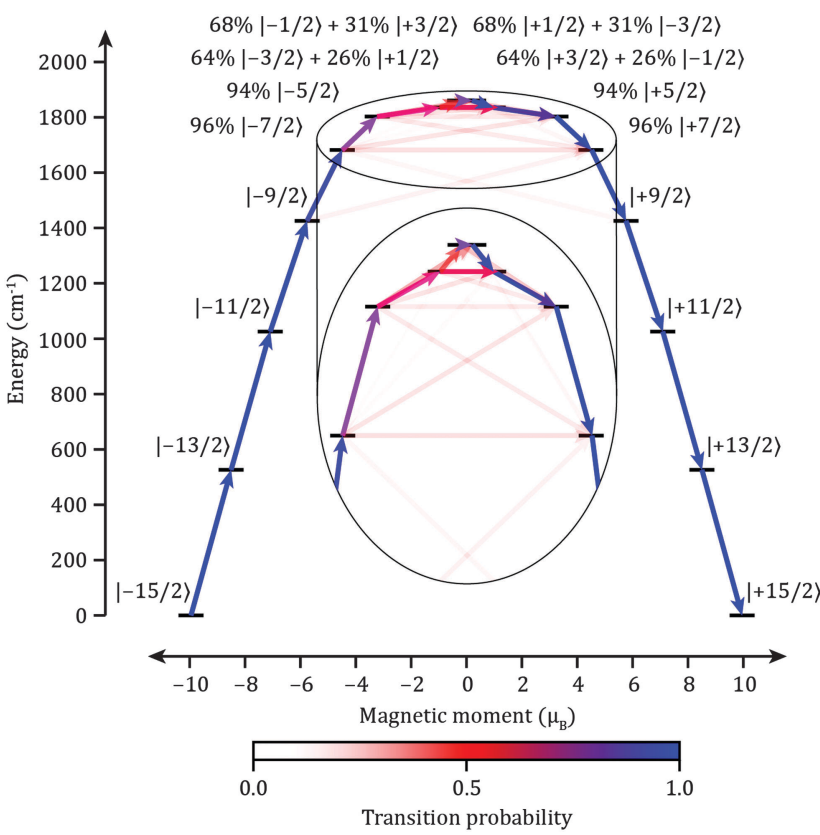

Fig. 3 Electronic states and magnetic transition probabilities for the ground ${ }^{6} \mathrm{H}_{15 / 2}$ multiplet of $\mathbf{2}$ in zero field. The $\boldsymbol{x}$-axis shows the magnetic moment of each state along the main magnetic axis of the molecule. Relaxation commences from the $|-15 / 2\rangle$ state and only includes pathways which reverse the magnetization. Relaxation probabilities are calculated based on a magnetic perturbation and are normalized from each departing state (see ESI† for details).

is excellent (Fig. S2 and S3, ESI $\dagger$ ). Dy ${ }^{\text {III }}$ has a ${ }^{6} \mathrm{H}_{15 / 2}$ ground multiplet, which is split by the crystal field into eight Kramer's doublets with total angular momentum projections $m_{J}= \pm 1 / 2, \pm 3 / 2, \ldots \pm 15 / 2$. The $a b$ initio calculations show that the lowest six Kramers doublets are the almost pure $m_{J}$ states of $m_{J}= \pm 15 / 2, \pm 13 / 2, \pm 11 / 2, \pm 9 / 2, \pm 7 / 2$ and $\pm 5 / 2$, sharing a common quantization axis (Fig. 3 and Tables S1 and S2, ESI $\dagger$ ). The two most energetic doublets are strongly mixed; a characteristic of low symmetry complexes due to the lack of a rigorous molecular $\mathrm{C}_{\infty}$ axis. ${ }^{14}$ Along the main magnetic axis these two states can be expressed as $\left|\psi_{\mathrm{ab}}\right\rangle=64 \%| \pm 3 / 2\rangle+$ $26 \%|\mp 1 / 2\rangle$ and $\left|\psi_{\mathrm{cd}}\right\rangle=68 \%| \pm 1 / 2\rangle+31 \%|\mp 3 / 2\rangle$ and (Table S2, ESI $\dagger$ ), giving the most energetic Kramers doublet a large $g_{y}$ value of $\sim 17.5$ perpendicular to the main magnetic axis.

Magnetic relaxation in lanthanides follows three possible routes: (1) QTM within the ground doublet (e.g. $|-15 / 2\rangle \rightarrow$ $|+15 / 2\rangle$ in Fig. 3), (2) thermally assisted QTM (TA-QTM) via excited states $($ e.g. $|-15 / 2\rangle \rightarrow|-13 / 2\rangle \rightarrow|+13 / 2\rangle \rightarrow|+15 / 2\rangle)$, or (3) an Orbach process composed of direct and/or Raman mechanisms $($ e.g. $|-15 / 2\rangle \rightarrow|-13 / 2\rangle \rightarrow|+15 / 2\rangle)$. The most probable pathway depends on the composition of the states involved and their interactions with phonons. For example, the slow magnetic relaxation for $\left\{\mathrm{Dy}_{4} \mathrm{~K}_{2}\right\}$ was shown to occur via the first or second excited states (TA-QTM), depending on the number and location of neighboring $\mathrm{Dy}^{\mathrm{III}}$ ions providing a source of transverse magnetic field. ${ }^{7}$ The states with opposing magnetic projections are mixed proportionally to the product of the transverse field and the transverse $g$-factors and therefore TA-QTM will occur via the excited state which has transverse 
$g$-factors above a certain threshold or where its main magnetic axis is non-collinear with that of the ground state. All non-QTM transitions are induced by the vibrational modes of the lattice (phonons) which create local oscillating magnetic fields through modulation of dipolar fields as well as an oscillating crystal field potential. ${ }^{23}$ To a first approximation, we can associate the probability of a phonon induced transition with the average magnetic ${ }^{13,14,24}$ and crystal field perturbation matrix elements (see ESI $\dagger$ for details).

Compared to all known Dy ${ }^{\text {III }}$ complexes the calculated properties for $\mathbf{2}$ are unique with very small transverse $g$-factors and a common principal axis for the lowest six Kramers doublets. This suggests that both the probability of QTM within the ground doublet and TA-QTM is vanishingly small until the two most energetic doublets. Orbach relaxation is also strongly disfavoured in the low lying states as magnetic transition probabilities due to phonons are miniscule (Fig. 3). Efficient magnetic relaxation will only occur via the highest energy doublets (Fig. 3, Fig. S4 and Tables S4 and S5, ESI $\dagger$ ). Therefore the $a b$ initio calculation predicts $U_{\text {eff }} \approx 1800 \mathrm{~cm}^{-1}$ for 2 - far greater than any complex to date. Whilst such calculations may over-estimate the energies of the crystal field states, ${ }^{25,26}$ we can predict a $T_{\mathrm{B}}$ in excess of $77 \mathrm{~K}$ as such temperatures are often around 1/20th of the $U_{\text {eff }}$ value if QTM within the ground doublet is disfavored, e.g. the $T_{\mathrm{B}} / U_{\text {eff }}$ ratios for $\left\{\mathrm{Tb}_{2} \mathrm{~N}_{2}{ }^{3-\bullet}\right\},\left\{\mathrm{Mn}_{12}\right\}$ and $\left\{\mathrm{Mn}_{6}\right\}$ are approximately $1 / 16,1 / 15$ and $1 / 13 \mathrm{~cm}^{-1} \mathrm{~K}^{-1}$, respectively. Calculations for the $\mathrm{Tb}^{\mathrm{II}}$ analogue 3, which is also a $4 \mathrm{f}^{9}$ ion, predict analogous behavior to 2 (Table S6, ESI $\dagger$ ). The high local symmetry at the Dy ${ }^{\text {III }}$ site implies that the nuclear quadrupole and hyperfine interactions will be axially symmetric, preventing efficient QTM within the lower energy doublets.

To examine the stability of 2 , we have performed $a b$ initio calculations for modified geometries where the $\mathrm{N}-\mathrm{Dy}-\mathrm{N}$ angle and the Dy- $\mathrm{N}$ bond lengths have been altered by $\pm 0.5^{\circ}$ and $\pm 0.01 \AA$, respectively (Fig. S5, ESI $\dagger$ ). The results show that 2 is stabilized when the Dy- $\mathrm{N}$ bond length is shortened and the $\mathrm{N}-\mathrm{Dy}-\mathrm{N}$ angle is closer to $180^{\circ}$ compared to 1 , yielding more favorable electronic properties. These calculations do not take into account the inclusion of a counter-ion in the structure, which may have consequences for crystal packing and the local structure of 2 .

Compound $\mathbf{1}$ is the first near-linear bis(amide) 4f-block complex. It allows us to propose a blueprint for the first generation of 'high-temperature' SMMs, with blocking temperatures exceeding that of liquid $\mathrm{N}_{2}(77 \mathrm{~K})$. The synthesis of the proposed archetypes, viz. the ${ }^{\mathrm{Dy}}{ }^{\mathrm{III}}$ and $\mathrm{Tb}^{\mathrm{II}}$ analogues of $\mathbf{1}$, is currently underway in our laboratory, however we believe this is a target many other groups should be pursuing. Calculations on other $\mathrm{f}^{n}$ ions suggest that $\mathrm{f}^{9}$ is ideal; even for the oblate $\mathrm{f}^{8}$ $\mathrm{Tb}^{\mathrm{III}}$ analogue, 4 , we find that the pseudo-doublets show strong mixing between the $\left|-m_{J}\right\rangle$ and $\left|+m_{J}\right\rangle$ projections, (Tables S7 and S8, ESI $\dagger$ ), which would lead to strong zero-field QTM.

While 2 would have a huge $U_{\text {eff }}$, an even higher $U_{\text {eff }}$ barrier might be possible if dianionic monodentate ligands could be incorporated, e.g. $\left.\left[{ }^{\mathrm{i}} \mathrm{Pr}_{3} \mathrm{Si}\right)_{2} \mathrm{C}-\mathrm{Dy}-\mathrm{C}\left(\mathrm{Si}^{\mathrm{i}} \mathrm{Pr}_{3}\right)_{2}\right]^{-}$, containing dianionic methanediides. Our preliminary results suggest this could raise $U_{\text {eff }}$ by a factor of 1.2 to 1.3. The incredible advances made in low coordination number metal-organic compounds in the last decade suggest that such hypothetical complexes are now chemically feasible. These metal-organic compounds are becoming of great importance in molecular magnetism. ${ }^{8,10,27,28}$

This work was supported by the EPSRC (grant number EP/K039547/1) (UK). N.F.C. thanks The University of Manchester for a President's Doctoral Scholarship. R.E.P.W. thanks The Royal Society for a Wolfson research merit award. We would like to thank J. P. S. Walsh for assistance with graphics.

\section{Notes and references}

1 R. Sessoli, D. Gatteschi, A. Caneschi and M. A. Novak, Nature, 1993, 365, 141.

2 D. Gatteschi, R. Sessoli and J. Villain, Molecular Nanomagnets, Oxford University Press, 2006.

3 L. Sorace, C. Benelli and D. Gatteschi, Chem. Soc. Rev., 2011, 40, 3092.

4 N. Ishikawa, M. Sugita, T. Ishikawa, S. Koshihara and Y. Kaizu, J. Am. Chem. Soc., 2003, 125, 8694.

5 D. N. Woodruff, R. E. P. Winpenny and R. A. Layfield, Chem. Rev., 2013, 113, 5110 .

6 C. R. Ganivet, B. Ballesteros, G. de la Torre, J. M. Clemente-Juan, E. Coronado and T. Torres, Chem. - Eur. J., 2013, 19, 1457.

7 R. J. Blagg, L. Ungur, F. Tuna, J. Speak, P. Comar, D. Collison, W. Wernsdorfer, E. J. L. McInnes, L. F. Chibotaru and R. E. P. Winpenny, Nat. Chem., 2013, 5, 673.

8 J. D. Rinehart, M. Fang, W. J. Evans and J. R. Long, J. Am. Chem. Soc., 2011, 133, 14236.

9 D. Gatteschi, Nat. Chem., 2011, 3, 830.

10 J. D. Rinehart, M. Fang, W. J. Evans and J. R. Long, Nat. Chem., 2011, 3, 538-542.

11 J. D. Rinehart and J. R. Long, Chem. Sci., 2011, 2, 2078.

12 N. F. Chilton, D. Collison, E. J. L. McInnes, R. E. P. Winpenny and A. Soncini, Nat. Commun., 2013, 4, 2551.

13 L. Ungur, J. J. Le Roy, I. Korobkov, M. Murugesu and L. F. Chibotaru, Angew. Chem., Int. Ed., 2014, 53, 4413.

14 L. Ungur and L. F. Chibotaru, Phys. Chem. Chem. Phys., 2011, 13, 20086.

15 (a) F. Mares, K. Hodgson and A. Streitwieser, Jr., J. Organomet. Chem., 1970, 24, C68; (b) K. R. Meihaus and J. R. Long, J. Am. Chem. Soc., 2013, 135, 17952.

16 For example, J. G. Brennan, F. G. N. Cloke, A. A. Sameh and A. Zalkin, Chem. Commun., 1987, 1668.

17 J. M. Zadrozny, D. J. Xiao, M. Atanasov, G. J. Long, F. Grandjean, F. Neese and J. R. Long, Nat. Chem., 2013, 5, 577.

18 C. Eaborn, P. B. Hitchcock, K. Izod and J. D. Smith, J. Am. Chem. Soc., 1994, 116, 12071.

19 C. Eaborn, P. B. Hitchcock, K. Izod, Z.-R. Lu and J. D. Smith, Organometallics, 1996, 15, 4783.

20 G. Qi, Y. Nitto, A. Saiki, T. Tomohiro, Y. Nakayama and H. Yasuda, Tetrahedron, 2003, 59, 10409.

21 W. J. Evans, D. K. Drummond, H. Zhang and J. L. Atwood, Inorg. Chem., 1988, 27, 575.

22 (a) G. Karlström, R. Lindh, P.-Å. Malmqvist, B. O. Roos, U. Ryde, V. Veryazov, P.-O. Widmark, M. Cossi, B. Schimmelpfennig and P. Neogrady, et al., Comput. Mater. Sci., 2003, 28, 222; (b) V. Veryazov, P. Widmark, L. Serrano-Andrés, R. Lindh and B. O. Roos, Int. J. Quantum Chem., 2004, 100, 626; (c) F. Aquilante, L. De Vico, N. Ferré, G. Ghigo, P. Malmqvist, P. Neogrády, T. B. Pedersen, M. Pitoňák, M. Reiher and B. O. Roos, et al., J. Comput. Chem., 2010, 31, 224; (d) L. F. Chibotaru and L. Ungur, J. Chem. Phys., 2012, 137, 064112.

23 A. Abragam and B. Bleaney, Electron Paramagnetic Resonance of Transition Ions, Oxford University Press, 1970.

24 L. Ungur, M. Thewissen, J.-P. Costes, W. Wernsdorfer and L. F. Chibotaru, Inorg. Chem., 2013, 52, 6328.

25 R. Marx, F. Moro, M. Dörfel, L. Ungur, M. Waters, S. D. Jiang, M. Orlita, J. Taylor, W. Frey, L. F. Chibotaru and J. van Slageren, Chem. Sci., 2014, 5, 3287.

26 E. Moreno Pineda, N. F. Chilton, R. Marx, M. Dörfel, D. O. Sells, P. Neugebauer, S.-D. Jiang, D. Collison, J. van Slageren, E. J. L. McInnes and R. E. P. Winpenny, Nat. Commun., 2014, 5, 6243.

27 F. Moro, D. P. Mills, S. T. Liddle and J. van Slageren, Angew. Chem., Int. Ed., 2013, 52, 3430.

28 R. A. Layfield, Organometallics, 2014, 33, 1084. 